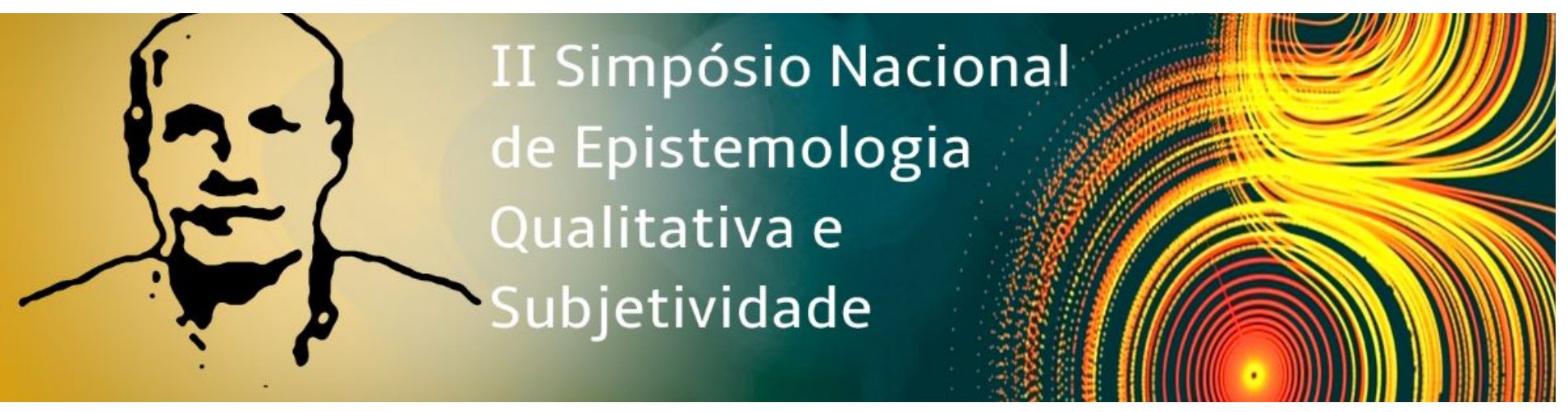

Eixo temático: Epistemologia Qualitativa e metodologia construtivo-interpretativa: discussões conceituais e relações com outras perspectivas epistemológicas e metodológicas;

\title{
Epistemologia Qualitiativa e etnografia: relação social e recursividade na pesquisa científica.
}

Diego Andres Barrios Díaz (Mestre/UnB) dub.diego@gmail.com

\section{Resumo}

Este é o começo de um estudo que busca inserir a Epistemologia Qualitativa de González Rey em um debate com outros campos epistemológicos e metodológicos das Ciências Sociais. Trata-se de compreender alguns desdobramentos desta proposta epistemológica e metodológica para lançar diálogos com outras formas de investigação. Fica registrada desde já a seguinte questão: como ampliar os alcances da Epistemologia Qualitativa e encontrar pontes com outras áreas e disciplinas? A presente discussão gira em torno do tema da emergência da inventividade do pesquisador no curso da pesquisa, aspecto que assume grande centralidade na sua obra ao definir o caráter ativo do pesquisador no curso da pesquisa (González Rey, 2005; 2017).

A partir de suas críticas às formas tradicionais de pesquisa em que o autor desaparece como sujeito concreto de criação, busca-se uma aproximação entre sue pensamento e as perspectivas etnográficas que têm orientado a proposta metodológica da antropologia. Sem deixar de considerar as grandes diferenças entre tais referenciais teóricos, este trabalho se propõe a pensar possíveis relações epistemológicas entre o pensamento de González Rey e este outro fazer metodológico no que diz respeito a um aspecto fundamental: o processo dialógico de comunicação vivido no contexto de pesquisa.

O antropólogo brasileiro Roberto Cardoso de Oliveira (1998) chamaria tal processo de um encontro de horizontes. As compreensões são de matrizes distintas, mas ambas situam o pesquisador diante da complexidade do outro. O autor se refere neste obra a uma "unidade 


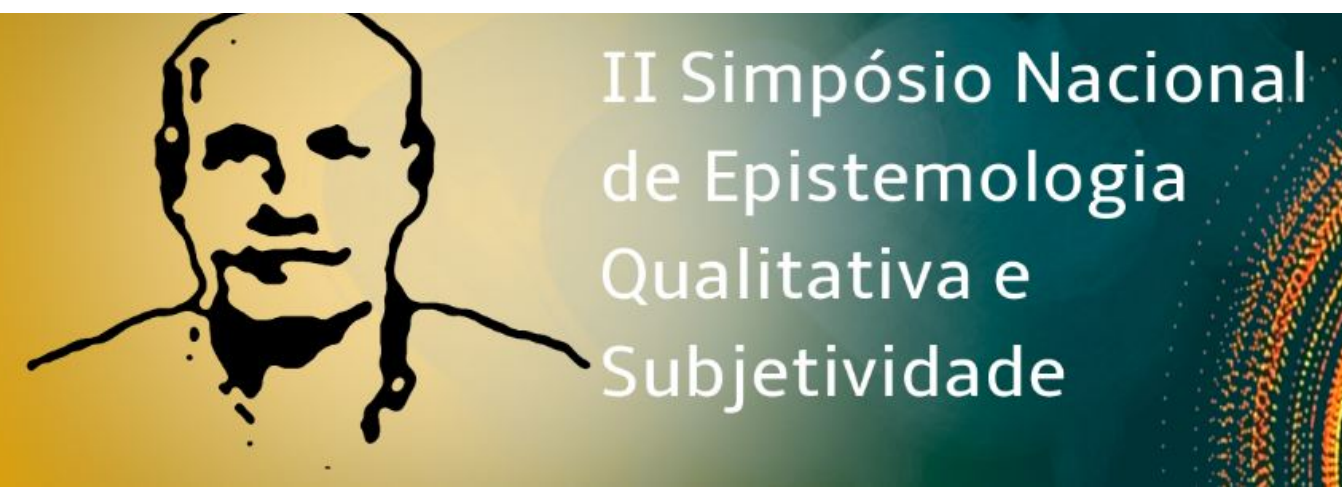

irredutível "entre 3 aspectos da construção científica - "olhar, ouvir e escrever". Há um investimento na escuta como ato dialógico que parece próximo do entendimento que González Rey propõe em sua metodologia.

Cardoso de Oliveira segue em sua argum"entação, discutindo os modelos nativos - "a matéria prima para o entendimento antropológico. As formulações teóricas aqui também se desenvolvam a partir da produção do autor no curso da relação de pesquisa. Tais formulações se constituem redes de informação e de sentido, assim, os conceitos e categorias não são exteriores e anteriores ao processo de pesquisa: eles se articulam a partir de um processo contínuo de interpretação.

Consciente da rigidez dos métodos de observação neutra, a antropologia nos ajuda a compreender a relação social como ponto de partida para a produção de conhecimento científico. Vejamos o que diz Vieira (2013):

Toda a observação e toda a interpretação são seletivas. O que o etnógrafo consigna é apenas parte de um todo mais amplo. E o real de que ele fala é, em parte, o real que ele fabrica. Mas não o pode fabricar a partir de um conhecimento exterior. (Vieira, 2013, p. 114).

Ao dar centralidade à emergência do sujeito pesquisador, torna-se fundamental pensar no desenvolvimento de bases éticas sólidas que sustentem a relação e o encontro com os horizontes da vida humana que nos propomos a conhecer. $\mathrm{O}$ objetivo aqui é reunir recursos para pensar o pesquisador como indivíduo histórico imerso em uma trama, um sujeito cujos valores e representações estão envolvidas no processo contínuo de síntese teórica no desenvolvimento do campo empírico.

Palavras chave: Epistemologia qualitativa, etnografia, ciências sociais.

\section{Referências}

CARDOSO DE OLIVEIRA, Roberto. O Trabalho do Antropólogo. Brasília/ São Paulo: Paralelo Quinze/Editora da Unesp,1998.

GONZÁLEZ REY, F. ; MITJÁNS MARTINEZ, A. Subjetividade: teoria, epistemologia e 


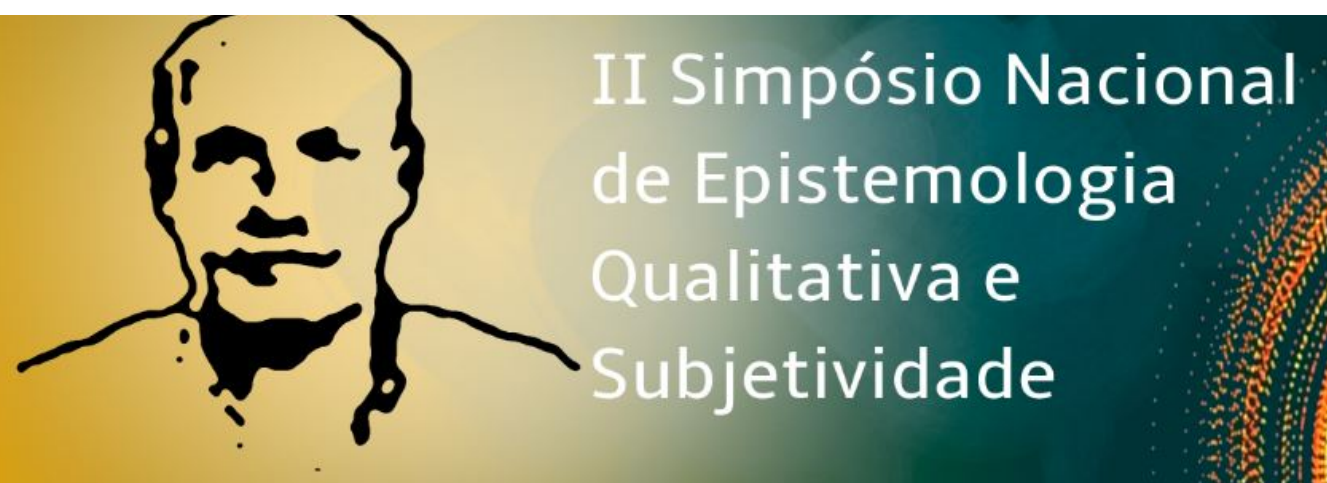

método. Campinas: Alínea. 2017.

GONZÁleZ REY, Fernando Pesquisa Qualitativa e Subjetividade: Os processos de construção da informação. São Paulo: Thomson Learning, 2005.

VIEIRA, Ricardo. Etnobiografias e descoberta de si: uma proposta da Antropologia da Educação para a formação de professores para a diversidade cultural. ProPosições, Campinas, v. 24, n. 2, p. 109-123, ago. 2013. 